\title{
Developing waist-to-height ratio cut-offs to define overweight and obesity in children and adolescents
}

\author{
Smita Nambiar*, lan Hughes and Peter SW Davies \\ School of Medicine, Children's Nutrition Research Centre, The University of Queensland, Herston, QLD 4029, \\ Australia
}

Submitted 12 January 2009: Accepted 26 November 2009: First published online 26 January 2010

\begin{abstract}
Objective: The waist-to-height ratio (WHtR) assesses abdominal adiposity and has been proposed to be of greater value in predicting obesity-related cardiovascular health risks in children than BMI. The present study aims to develop WHtR cutoffs for overweight and obesity based on the 85th and 95th percentiles for the percentage body fat $(\% \mathrm{BF})$ in a cohort of children and adolescents.

Design: Waist circumference (WC), height, triceps and subscapular skinfolds were used to calculate WHtR and \%BF. Correlations between WHtR and \%BF and WHtR/mid-abdominal skinfold were made. Receiver-operating characteristic (ROC) curve analysis was used to select WHtR cut-offs to define overweight and obesity. Subjects were grouped by WHtR cut-offs, and mean values for anthropometry, blood lipids and blood pressure (BP) variables were compared.

Setting: Australian primary and secondary schools.

Subjects: A total of 2773 male (M) and female (F) subjects of the 1985 Australian Health and Fitness Survey, aged 8-16 years.

Results: Correlation coefficients between WHtR and \%BF were M: $r=0 \cdot 73, \mathrm{~F}: r=0 \cdot 60$, $P<0 \cdot 01$ and $\mathrm{WHtR} /$ mid-abdominal skinfold were $\mathrm{M}: r=0 \cdot 78, \mathrm{~F}: r=0 \cdot 65, P<0 \cdot 01$. WHtR of $0 \cdot 46(\mathrm{M})$ and $0 \cdot 45(\mathrm{~F})$ best identified subjects with $\geq 85$ th percentile for $\% \mathrm{BF}$ and $0 \cdot 48(\mathrm{M})$ and $0 \cdot 47(\mathrm{~F})$ identified subjects with $\geq 95$ th percentile for $\% \mathrm{BF}$. When comparing the highest WHtR group to the lowest, both sexes had significantly higher means for weight, WC, \%BF, TG (male subjects only), systolic BP (female subjects only) and lower means for HDL cholesterol $(P<0 \cdot 05)$.

Conclusions: WHtR is useful in clinical and population health as it identifies children with higher $\% \mathrm{BF}$ at greater risk of developing weight-related CVD at an earlier age.
\end{abstract}

Keywords
Children
Obesity
Cardiovascular comorbidities
WHtR cut-offs

Obesity is an escalating health issue in the paediatric population $^{(1-3)}$. Overweight and obese children and adolescents are at greater risk of insulin resistance, high insulin levels and apoprotein $\mathrm{B}$, high concentrations of LDL cholesterol (LDL-C) and TAG and low concentrations of HDL cholesterol (HDL-C) ${ }^{(4,5)}$ Excessive accumulation of body fat (BF), particularly in the abdominal region, is associated with CVD in adults ${ }^{(3,4,6-9)}$.

Anthropometric measurements such as BMI and waist circumference (WC) are widely used to categorise individuals of all ages as normal, overweight or obese ${ }^{(10,11)}$. The BMI is a proxy for body size ${ }^{(12)}$, whereas the WC measure reflects subcutaneous and visceral fat depots and can predict health risks in adults and children as young as 10 years of age ${ }^{(10)}$.

Although both BMI and WC are simple to calculate and interpret, they do come with disadvantages. The BMI, for instance, cannot differentiate between muscle, bone or fat mass. BMI is only correlated with total adiposity, without addressing the distribution of $\mathrm{BF}^{(10,13,14)}$. The $\mathrm{WC}$, on the other hand, is more representative of $\mathrm{BF}$ distribution and is focused on, anatomically, as fat associated with the greatest health risk $^{(7,11,15)}$. It has been shown to predict health risks associated with being overweight, although notably, there are no definitive cut-offs to mark elevated CVD health risks in children. Both these measures are also age- and sex- dependent. Unless appropriate cut-offs are known, knowledge of BMI and WC alone is not enough to distinguish whether the subject is underweight, overweight or obese. Although some BMI charts (US Centers for Disease Control growth charts or International Obesity Task Force (IOTF) charts) are used internationally, countries also use their own data with varying cut-offs to define overweight and obesity ${ }^{(16,17)}$. It is especially difficult to make international comparisons using WC data, because again, different countries use their own reference data, cut-points for health risks vary and WC measurement sites differ.

The waist-to-height ratio (WHtR) is an index developed relatively recently, calculated by dividing the WC (commonly at the level of the umbilicus) by height, both measured in centimetres ${ }^{(18)}$. This index may be superior 
to BMI and WC, because it incorporates the WC as a measure of abdominal adiposity, but also adjusts for the size of the individual by dividing by their height. The use of this index has been proposed because of its ability to explain the metabolic consequences of obesity and identify abdominal obesity, particularly in individuals who may not be classed as overweight or obese by $\mathrm{BMI}^{(18-27)}$. In male and female adults, a WHtR value of $\geq 0.5$ classifies the individual (who may or may not be overweight according to BMI) to be at significantly greater risk of the metabolic syndrome and cardiovascular comorbidities than a person with a WHtR $<0 \cdot 5^{(26,27)}$. This WHtR cut-off was established based on studies that assessed strengths of associations between body composition, $\mathrm{BF}$ distribution and tests to assess cardiovascular health, such as blood pressure (BP) and blood lipid profiles (total cholesterol (T-Chol), TAG, LDL-C and HDL-C) ${ }^{(18-25,28-32)}$. Statistical analysis using correlations and receiver-operating characteristic (ROC) curve analysis found that cut-offs close to 0.5 to be most sensitive in correctly identifying persons with elevated cardiovascular health risks. It has been suggested that a cut-off of 0.5 is suitable to apply to children and adolescents, independent of age and sex. Although we have previously shown that this index is a statistically acceptable index for use in children and adolescents ${ }^{(19)}$, the sensitivity of using a cut-off of 0.5 to identify abdominal obesity or risk of CVD in children and adolescents has not been investigated ${ }^{(18,20-25,28,29)}$.

The present study aims to derive appropriate WHtR cutoffs based on percentage BF (\%BF) to identify children and adolescents with greater abdominal adiposity, as these children may have an increased risk of developing CVD. Earlier studies have developed WHtR cut-offs for children with selected WHtR cut-offs based on ROC analysis using BMI cut-offs for overweight and obesity. Developing WHtR cut-offs based on BMI is not entirely appropriate, as BMI cannot differentiate between fat mass and fat-free mass, does not specifically recognise abdominal fat, and is the measure with which WHtR is being compared. The WHtR cut-offs derived in the present study will be based on the 85th (overweight) and 95th (obese) percentiles for $\% \mathrm{BF}^{(34)}$. The criteria for selecting a cut-off will be based on the following considerations: high sensitivity $(\sim 80 \%$ and higher) and specificity ( $\sim 70 \%$ and higher), if possible, independent of sex and/or age.

\section{Methodology}

\section{Survey}

Data from the 1985 Australian Health and Fitness Survey were used in the analysis. This National Survey was conducted to establish benchmark data on fitness levels, health and physical performance of 8484 boys and girls, between the ages of 7 and 16 years, in all six states and two territories of Australia ${ }^{(20)}$. The students were approached in a school setting.
In this survey, 2773 (out of the 8484) subjects were included, as only these subjects could provide the skinfold measurements needed to calculate \%BF. As many of the technical and laboratory tests, such as skinfolds, BP and collection and analysis of blood samples, were time consuming and expensive to administer, they were predominantly measured in students aged 9, 12 and 15 years. These ages were selected to approximate prepuberty, puberty and postpuberty ${ }^{(20)}$. Children aged 7 years were excluded from the survey, as there were only four subjects who could provide all the required information. All 2773 subjects provided information on age, height, weight, WC, BMI, WHtR, triceps and subscapular skinfolds to calculate $\% \mathrm{BF}$ and mid-abdominal skinfolds. Of the 2773 subjects, $97 \%$ could provide information on systolic (SBP) and diastolic (DBP) blood pressure, and approximately $60 \%$ could provide information on blood lipids (due to fewer consenting subjects, unfasted subjects or insufficient amounts of blood samples for analysis).

Height $(\mathrm{cm})$ was measured using either a KaWe Height tape or rigid metric measuring tape and plastic set square to the nearest $0 \cdot 1 \mathrm{~cm}$. Students were measured in bare feet. Weight $(\mathrm{kg})$ was measured using beam or medical spring scales to the nearest $0.5 \mathrm{~kg}$. The weighing procedure was repeated until two consecutive weight measures that were the same were obtained. Students wore their sports uniform. Excess clothing and jewellery were removed. WC (at the level of the umbilicus) was measured in centimetres, to the nearest $0 \cdot 1 \mathrm{~cm}$, using a flat, spring-loaded metal (constant tension) tape ${ }^{(20)}$.

Skinfold measurements were taken using Holtain calipers. Anatomical landmarks for the measurement sites were marked with a pencil. For triceps, a point was marked on the back of the right arm midway between the acromion process of the scapular and olecranon of the ulna. The subject then stood with both arms relaxed by their side. The skin was lifted $1 \mathrm{~cm}$ above the mark and the calipers were applied on the mark. For the subscapular skinfold, the skin was marked $1 \mathrm{~cm}$ below the inferior angle of the scapular on the right side. A fold running downward and laterally at an angle of 30 degrees was picked up, $1 \mathrm{~cm}$ from the marked point. The calipers were applied on the mark. For the mid-abdominal skinfold, the skin was marked $2 \mathrm{~cm}$ to the right of the umbilicus. The fold was lifted vertically $1 \mathrm{~cm}$ above the mark. The calipers were placed on the mark. For all measures, the grip on the calipers was released to exert full pressure on the folds. Two measurements were taken at each site and a third measure was taken if the first two were not the same ${ }^{(20)}$.

Height and weight measures were used to calculate BMI (weight $/ \mathrm{ht}^{2}$ ). WC and height were used to calculate WHtR (WC/ht). The triceps and subscapular skinfold measurements were used in the prediction equations of Slaughter et $a l^{(21)}$ to obtain \%BF.

The subjects were classified according to $\% \mathrm{BF}$ as overweight ( $\geq 85$ th percentile) and obese ( $\geq 95$ th percentile) 
using the criteria of McCarthy et al. (2006) ${ }^{(22)}$. These British percentiles were used, because at present, Australia does not have \%BF percentiles for children. In McCarthy et al.'s (2006) study, bioelectrical impedance was used to measure \%BF. In developing \%BF percentiles, these workers took geography, ethnicity, socio-economics, nutrition and timing (secular increases in obesity prevalence) into consideration and matched their sample closely to the BMI charts and the British 1990 growth reference sample. The mean BMI Z-score of McCarthy et al.'s (2006) sample was $-0 \cdot 13$ with an SD of $1 \cdot 19$. Their $\% \mathrm{BF}$ curves were also found to be similar to the curves published by a US study ${ }^{(23)}$, with the 50 th percentile curves agreeing closely between the US and British cohorts ${ }^{(22,23)}$.

The students fasted for at least $12 \mathrm{~h}$ before blood collection. Blood was also collected from non-fasting subjects; however, these subjects were excluded from our analysis. Students were rested for at least $10 \mathrm{~min}$ in a quiet room before taking a sample. A $15 \mathrm{ml}$ sample was collected from each student from an antecubital vein in the right $\operatorname{arm}^{(24)}$. The samples were analysed to provide T-Chol, TAG and HDL-C. LDL-C was calculated using the Friedewald formula ${ }^{(25)}$.

BP was measured using a mercury sphygmomanometer and a stethoscope. Both child- and adult-sized cuffs were available for use, depending on the size of the child's upper arm. A quiet room was selected for testing. The students were asked to remain quietly seated for $5 \mathrm{~min}$ before measurement. Measurement was taken while the student was seated, with the left arm resting on the desk, elbow level with the heart. The stethoscope was placed on the cubital fossa of the brachial artery. The sphygmomanometer was pumped to $180 \mathrm{mmHg}$, and pressure was released at a rate of $2 \mathrm{mmHg} / \mathrm{s}$ (the rate was not allowed to exceed $2 \mathrm{mmHg} / \mathrm{s}$ ). Pressures at which Korotkoff sounds I (SBP), IV and V (DBP) were heard were recorded. The procedure was repeated, and the averages of the SBP and DBP were recorded. The averages for SBP and DBP (Korotkoff sound IV) were used in our analysis.

\section{Statistical analysis}

ANOVA post boc tests were initially carried out to see whether any of the individual age groups differed from each other with statistical significance for $\% \mathrm{BF}$ and WHtR. If there were no noted differences, then age bands could be formed, with each band consisting of three age groups, thus minimising the number of required WHtR cut-offs. ANOVA post boc tests revealed that the only statistically significant difference existed between the male subjects for age groups 9 and 12 years for \%BF, and female subjects for age groups 9 and 12 years for WHtR. These groups were, therefore, kept separate, by forming the following age bands: 8.00-10.99, 11.00-13.99 and $14 \cdot 00-16.99$ years.

$t$ Tests were carried out to note any difference between male and female subjects for selected variables. Correlations were initially carried out for WHtR and \%BF and WHtR and mid-abdominal skinfold by sex and age. Steiger's $Z$-test was used to find whether differences between correlations were statistically significant.

ROC analysis (by age bands and sex) was carried out in the next stage of analysis to find the WHtR cut-offs with the highest sensitivity ( $\sim 80 \%$ or higher) and specificity ( $\sim 70 \%$ and higher) to identify children either above the 85 th (overweight) or 95 th (obese) percentiles for $\% \mathrm{BF}$. ROC analyses were also carried out to compare the sensitivity of BMI, WC and the newly proposed cut-offs in identifying subjects with $\geq 95$ th percentile of $\% \mathrm{BF}$.

ANOVA post hoc tests were carried out to look for statistically significant differences in the means for anthropometric, blood lipid and BP variables when subjects were grouped by sex and new WHtR categories.

Statistical analysis was conducted using Statistical Package for the Social Sciences statistical software package version $17 \cdot 0$ (SPSS Inc., Chicago IL, USA, 2008). Steiger's $Z$-test was calculated using Cal's Computators FZT ${ }^{(26)}$.

\section{Results}

Table 1 provides summary statistics for selected variables by age band and sex. Within the 8- to 10-year group, the mean WC of male subjects was significantly larger than that of female subjects. This was also the case in the 11-13-year group, whereas the female subjects of this age group were also significantly taller. Among the 14-16-year-olds, height, weight and WC were all significantly greater in male subjects, whereas mean BMI was significantly higher in female subjects (mean BMI Z-score for the sample was 0.031 (SD 0.088); 95\% CI 0・002, 0•064).

Table 2 illustrates Pearson's correlation coefficients between WHtR and \%BF and mid-abdominal skinfold and $\% \mathrm{BF}$ by age and gender. Correlation coefficients were consistently higher between WHtR and mid-abdominal skinfold (males: $r=0 \cdot 78$, females: $r=0 \cdot 65, P<0 \cdot 01$ ) than between WHtR and \%BF (males: $r=0 \cdot 73$, females: $r=0 \cdot 60, P<0 \cdot 01$ ). Differences were statistically significant in all groups $(P<0 \cdot 0001)$ except for female subjects aged 14-16 years. Across all ages, all correlations were found to be stronger among male subjects than among female subjects with highest correlation male subjects in the 11-13-year age band.

Table 3 shows the results of the ROC analysis by age band and sex. The areas under the curve (AUC) for all age groups and both sexes ranged between 0.83 and 0.96 . Figure 1 shows the AUC to identify male subjects aged $11-13$ years with $\geq 95$ th percentile for $\% \mathrm{BF}$. In subjects aged 8-16 years, a WHtR cut-off that best identified subjects with $\geq 85$ th percentile for $\% \mathrm{BF}$ was 0.46 for male and 0.45 for female subjects. To identify those with $\geq 95$ th percentile for $\% \mathrm{BF}$, the most suitable cut-off was 0.48 in male subjects and 0.47 for female subjects. WHtR groups were thus defined in relation to $\% \mathrm{BF}$ : (i) $<85$ th percentile, (ii) $\geq 85$ th $-<95$ th percentile and (iii) $\geq 95$ th percentile. 
Table 1 Summary statistics for selected variables by age group and sex

\begin{tabular}{|c|c|c|c|c|c|c|c|c|c|c|c|}
\hline \multirow[b]{2}{*}{ Age band (years) } & \multirow[b]{2}{*}{ Variables } & \multicolumn{5}{|c|}{ Male } & \multicolumn{5}{|c|}{ Female } \\
\hline & & $n$ & Min & Max & Mean & SD & $n$ & Min & Max & Mean & SD \\
\hline \multirow[t]{7}{*}{$8-10$} & Age (years) & 477 & 8.03 & $10 \cdot 94$ & $9 \cdot 51$ & 0.43 & 482 & 8.06 & $10 \cdot 46$ & $9 \cdot 49$ & 0.40 \\
\hline & Height $(\mathrm{cm})$ & & $107 \cdot 80$ & $155 \cdot 30$ & $136 \cdot 10$ & $6 \cdot 00$ & & $116 \cdot 60$ & $157 \cdot 40$ & $135 \cdot 30$ & $6 \cdot 40$ \\
\hline & Weight (kg) & & $16 \cdot 50$ & $55 \cdot 00$ & $31 \cdot 60$ & $5 \cdot 70$ & & $20 \cdot 50$ & $61 \cdot 00$ & $31 \cdot 60$ & $5 \cdot 80$ \\
\hline & $W C(\mathrm{~cm})^{*}$ & & $50 \cdot 50$ & $94 \cdot 10$ & $60 \cdot 10$ & $6 \cdot 00$ & & $45 \cdot 50$ & $86 \cdot 50$ & $59 \cdot 20$ & $6 \cdot 30$ \\
\hline & BMI $\left(\mathrm{kg} / \mathrm{m}^{2}\right)$ & & 11.90 & $34 \cdot 70$ & $17 \cdot 00$ & $2 \cdot 30$ & & $12 \cdot 50$ & $26 \cdot 10$ & $17 \cdot 20$ & $2 \cdot 20$ \\
\hline & WHtR & & 0.36 & 0.68 & 0.44 & 0.04 & & 0.35 & 0.61 & 0.44 & 0.04 \\
\hline & $\% B F$ & & $6 \cdot 82$ & $48 \cdot 70$ & $15 \cdot 40$ & $5 \cdot 50$ & & $8 \cdot 20$ & $46 \cdot 50$ & $19 \cdot 30$ & $5 \cdot 60$ \\
\hline \multirow[t]{7}{*}{$11-13$} & Age (years) & 484 & $11 \cdot 08$ & $14 \cdot 00$ & $12 \cdot 51$ & 0.42 & 487 & $11 \cdot 03$ & $14 \cdot 00$ & $12 \cdot 53$ & 0.38 \\
\hline & Height $(\mathrm{cm})^{*}$ & & $125 \cdot 90$ & $176 \cdot 20$ & $151 \cdot 10$ & $7 \cdot 80$ & & 118.90 & $172 \cdot 00$ & 153.00 & $7 \cdot 00$ \\
\hline & Weight (kg) & & $23 \cdot 50$ & $94 \cdot 50$ & $42 \cdot 80$ & $9 \cdot 40$ & & $26 \cdot 00$ & $77 \cdot 00$ & $44 \cdot 20$ & $8 \cdot 50$ \\
\hline & $\mathrm{WC}(\mathrm{cm})^{*}$ & & $51 \cdot 10$ & $105 \cdot 20$ & $66 \cdot 90$ & $8 \cdot 50$ & & $50 \cdot 00$ & $107 \cdot 50$ & $64 \cdot 80$ & $7 \cdot 30$ \\
\hline & BMI $\left(\mathrm{kg} / \mathrm{m}^{2}\right)$ & & $13 \cdot 90$ & $30 \cdot 60$ & $18 \cdot 60$ & $2 \cdot 90$ & & $13 \cdot 60$ & $29 \cdot 70$ & $18 \cdot 80$ & $2 \cdot 70$ \\
\hline & $\mathrm{WH} \mathrm{tR}^{\star}$ & & 0.35 & 0.64 & 0.44 & 0.05 & & 0.34 & 0.68 & 0.42 & 0.04 \\
\hline & $\% \mathrm{BF}^{*}$ & & $5 \cdot 70$ & $50 \cdot 80$ & $17 \cdot 30$ & $7 \cdot 00$ & & $9 \cdot 50$ & $43 \cdot 80$ & $19 \cdot 80$ & $5 \cdot 70$ \\
\hline \multirow[t]{7}{*}{$14-16$} & Age (years) & 434 & $14 \cdot 81$ & $16 \cdot 17$ & $15 \cdot 40$ & 0.32 & 409 & $14 \cdot 02$ & $16 \cdot 10$ & $15 \cdot 45$ & 0.35 \\
\hline & Height $(\mathrm{cm})^{*}$ & & $132 \cdot 50$ & $194 \cdot 00$ & $170 \cdot 30$ & $7 \cdot 90$ & & $145 \cdot 00$ & $177 \cdot 70$ & $161 \cdot 60$ & $5 \cdot 90$ \\
\hline & Weight $(\mathrm{kg})^{*}$ & & $27 \cdot 50$ & $95 \cdot 50$ & $59 \cdot 80$ & $10 \cdot 10$ & & $38 \cdot 50$ & $86 \cdot 50$ & $55 \cdot 10$ & $8 \cdot 20$ \\
\hline & $W C(\mathrm{~cm})^{*}$ & & $58 \cdot 00$ & $106 \cdot 50$ & $73 \cdot 50$ & $6 \cdot 80$ & & $54 \cdot 60$ & $97 \cdot 80$ & $69 \cdot 70$ & $6 \cdot 90$ \\
\hline & BMI $\left(\mathrm{kg} / \mathrm{m}^{2}\right)^{*}$ & & $14 \cdot 40$ & $31 \cdot 5$ & $20 \cdot 50$ & $2 \cdot 60$ & & $15 \cdot 20$ & $31 \cdot 30$ & $21 \cdot 10$ & $2 \cdot 70$ \\
\hline & WHtR & & 0.36 & 0.61 & 0.43 & 0.04 & & 0.34 & 0.58 & 0.43 & 0.04 \\
\hline & $\% \mathrm{BF}^{*}$ & & $5 \cdot 10$ & $60 \cdot 90$ & $13 \cdot 70$ & $5 \cdot 30$ & & $9 \cdot 70$ & $44 \cdot 40$ & $22 \cdot 9$ & $5 \cdot 90$ \\
\hline
\end{tabular}

Min, minimum; Max, maximum; WC, waist circumference; WHtR, waist-to-height ratio; \%BF, percentage body fat.

${ }^{*}$ Statistically significant differences between male and female subjects for tested variable: $P<0.05$.

Table 2 Pearson's correlations between WHtR/\%BF and WHtR/ mid-abdominal skinfold by age group and gender

\begin{tabular}{lccc}
\hline $\begin{array}{l}\text { Age band } \\
\text { (years) }\end{array}$ & Sex & $\begin{array}{c}\text { WHtR } \\
\text { and \%BF }\end{array}$ & $\begin{array}{c}\text { WHtR and mid- } \\
\text { abdominal skinfold }\end{array}$ \\
\hline $8-10$ & M & 0.65 & 0.76 \\
& F & 0.61 & 0.70 \\
$11-13$ & M & 0.80 & 0.85 \\
& F & 0.67 & 0.74 \\
$14-16$ & M & 0.68 & 0.76 \\
All & M & 0.57 & 0.60 \\
& F & 0.73 & 0.78 \\
& 0.60 & 0.65 \\
\hline
\end{tabular}

WHtR, waist-to-height ratio; \%BF, percentage body fat; $\mathrm{M}$, male; $\mathrm{F}$, female All correlations are significant at $P<0.01$. WHtR/mid-abdominal skinfold correlations are statistically significantly higher than $\mathrm{WHtR} / \% \mathrm{BF}$ in all groups $(P<0 \cdot 0001)$ except for female subjects aged $14-16$ years.

Table 4 shows ROC analyses comparing the sensitivity and specificity of new WHtR cut-offs against existing BMI (IOTF) and WC (Australian percentiles) cut-offs for obesity by sex and selected age groups. BMI was found to have the lowest sensitivity than WC and WHtR. This was observed for both sexes and all selected age groups. Figure $1 \mathrm{a}-\mathrm{c}$ presents this graphically, using male subjects aged 12 years as an example.

Tables $5 \mathrm{a}$ and $\mathrm{b}$ report data for weight, WC, \%BF, blood lipids and BP. These have been stratified by sex and the newly developed WHtR cut-offs. ANOVA post hoc tests revealed that mean weight, $\mathrm{WC}$ and \%BF were significantly different between the WHtR groups and highest in WHtR group 3 for both sexes. For male subjects, age and height were significantly different between WHtR groups 1 and 2 . TAG levels were significantly higher and HDL-C levels were significantly lower in group 3 male subjects (HDL-C levels were also significantly different between groups 1 and 2 among male subjects). Mean HDL-C levels were significantly lower in group 3 female subjects than in group 1 female subjects $(P<0 \cdot 05)$. SBP was significantly different between groups 1 and 3 and 2 and 3 for female subjects (age and height, however, were not significantly different), with group 3 having the highest levels $(P<0 \cdot 05)$.

\section{Discussion}

There are several different anthropometric measurements and indices used to estimate aspects of body composition and assess body-related health status. With these measures, there are different cut-offs used to designate different health statuses, such as 'overweight' and 'obese'. In the present study, we aimed to further investigate the WHtR by developing cut-offs to define overweight and obesity based on \%BF.

Previous literature has found that the WHtR, rather than BMI and WC, was more strongly correlated with cardiovascular comorbidities and was better at predicting the metabolic syndrome in adults and cardiovascular health risks, such as high BP and high blood lipids, in adults and children $^{(18,27-37)}$.

In adults, a WHtR value of $\geq 0.5$ has been found to be associated with a greater risk of the metabolic syndrome, whether or not the person is classified as overweight by BMI. The 0.5 cut-off is used for male and female subjects of all ages and ethnicity ${ }^{(27,28)}$. 
Table 3 ROC analysis: selecting WHtR cut-off to identify male and female subjects with $\geq 85$ th and $\geq 95$ th percentiles for percentage body fat

\begin{tabular}{|c|c|c|c|c|c|c|c|}
\hline \multirow[b]{2}{*}{ Age band (years) } & \multirow[b]{2}{*}{ Variables } & \multicolumn{3}{|c|}{ Male } & \multicolumn{3}{|c|}{ Female } \\
\hline & & $n$ & 85th & 95th & $n$ & 85th & 95th \\
\hline \multirow[t]{6}{*}{$8-10$} & AUC & 477 & 0.90 & 0.96 & 482 & $0 \cdot 88$ & 0.90 \\
\hline & $\mathrm{SE}$ & & 0.02 & 0.02 & & 0.03 & 0.03 \\
\hline & $95 \% \mathrm{Cl}$ & & $0.86,0.95$ & $0.93,0.98$ & & $0.84,0.93$ & $0.85,0.96$ \\
\hline & Selected WHtR cut-off & & 0.46 & 0.48 & & 0.45 & 0.47 \\
\hline & Sensitivity (\%) & & $80 \cdot 0$ & $96 \cdot 0$ & & $91 \cdot 0$ & $93 \cdot 0$ \\
\hline & Specificity (\%) & & $79 \cdot 0$ & $90 \cdot 0$ & & $68 \cdot 0$ & $82 \cdot 0$ \\
\hline \multirow[t]{6}{*}{$11-13$} & AUC & 484 & 0.92 & 0.96 & 487 & 0.91 & 0.93 \\
\hline & SE & & 0.02 & 0.01 & & 0.02 & 0.03 \\
\hline & $95 \% \mathrm{Cl}$ & & $0.89,0.95$ & $0.94,0.98$ & & $0.87,0.96$ & $0.86,0.99$ \\
\hline & Selected WHtR cut-off & & 0.46 & 0.48 & & 0.45 & 0.47 \\
\hline & Sensitivity (\%) & & $82 \cdot 0$ & $91 \cdot 0$ & & $88 \cdot 0$ & $77 \cdot 0$ \\
\hline & Specificity (\%) & & $86 \cdot 0$ & $88 \cdot 0$ & & $80 \cdot 0$ & $88 \cdot 0$ \\
\hline \multirow[t]{6}{*}{$14-16$} & AUC & 434 & 0.90 & 0.95 & 409 & 0.83 & 0.82 \\
\hline & SE & & 0.03 & 0.03 & & 0.03 & 0.04 \\
\hline & $95 \% \mathrm{Cl}$ & & $0.85,0.96$ & $0.89,1 \cdot 00$ & & $0.78,0.88$ & $0.74,0.90$ \\
\hline & Selected WHtR cut-off & & 0.46 & 0.48 & & 0.45 & 0.47 \\
\hline & Sensitivity (\%) & & $74 \cdot 0$ & $88 \cdot 0$ & & $77 \cdot 0$ & $61 \cdot 0$ \\
\hline & Specificity (\%) & & $87 \cdot 0$ & $93 \cdot 0$ & & $73 \cdot 0$ & $83 \cdot 0$ \\
\hline
\end{tabular}

ROC, receiver-operating characteristic; WHtR, waist-to-height ratio; AUC, area under the curve.

It has been suggested that a cut-off of 0.5 is suitable to be applied to children and adolescents as well ${ }^{(27,28)}$. However, to date, no specific cut-offs have been developed to predict these cardiovascular health risks. There may be several reasons for this. Although research has shown that cardiovascular health risks are higher in obese children and adolescents who have a greater \%BF, distributed abdominally, they may not present with these risk factors until later in life, making it difficult to assess these risks in studies that are not longitudinal in design ${ }^{(9,15,38)}$. The cause of high lipid profiles may also be familial rather than weight related ${ }^{(9)}$.

WHtR cut-offs in the present study have been based on $\% \mathrm{BF}$. Strong positive correlations were found between $\% \mathrm{BF}$ and WHtR, with even higher correlations found between WHtR and the mid-abdominal skinfold. What these results illustrate is that WHtR not only does increase with increasing $\% \mathrm{BF}$, but also, more importantly, is strongly correlated with BF distributed abdominally. The mid-abdominal skinfold, a proxy measure of BF distribution, has been shown to be highly associated with subcutaneous and intra-abdominal fat ${ }^{(39,40)}$ and excess fat in the abdominal region that have been associated with cardiovascular health risks ${ }^{(40)}$. The WHtR has the added advantage of being much simpler to measure in large cohorts of children and obese subjects than various skinfold measures that require trained technicians and repeated measures to minimise technical errors. It was also noted that the correlation was stronger among male subjects than female subjects. This may be attributed to a wider range in body weight in male subjects than in female subjects.

This investigation found that the most sensitive WHtR cut-off to identify children having $\geq 85$ th percentile for $\%$ BF was $\geq 0.46$ for male subjects and $\geq 0.45$ for female subjects aged $8-16$ years. Sensitivity ranged from $73 \%$ to
91\% across the age groups. Selecting WHtR cut-offs for overweight and obesity with the best trade-off between sensitivity and specificity was much more difficult among the female subjects, especially of the oldest age group. This may be due to moderate correlations between WHtR and $\% \mathrm{BF}$, with only $32 \%$ of the variation in $\% \mathrm{BF}$ explained by WHtR in this age group. High sensitivity was a priority in selecting WHtR cut-offs, in order to make it an effective screening tool in population health studies involving large numbers of subjects, particularly children. Once it is recognised that these individuals are at significant risk for CVD, obtaining parental consent for further laboratory tests for blood lipid analyses may also prove to be easier.

BMI is presently the most widely used screening tool to define overweight and obese subjects, although research has shown that it is not well correlated with $\% \mathrm{BF}^{(41)}$. The results of the present study (Table 4 and Fig. 1a-c) also indicate that BMI, although highly specific, is significantly less sensitive than WHtR in identifying children with $\geq 95$ th percentile for $\% \mathrm{BF}$. WHtR was also compared to Australian percentiles for $\mathrm{WC}^{(42)}$. Again, the proposed WHtR cut-offs were found to be more sensitive. Another advantage of these WHtR cut-offs is that they are not dependent on age. This adds to its simplicity when compared to BMI and WC cut-offs for overweight and obesity that change with sex and age.

If a WHtR of 0.5 was used in this sample, as previously suggested, the sensitivity of the WHtR would greatly decrease. To identify those above the 85th percentile, sensitivity would fall to between $23 \%$ and $55 \%$ in male and female subjects at 8-16 years of age, whereas the sensitivity to identify those above the 95th percentile for $\% \mathrm{BF}$ would fall to between $30 \%$ and $70 \%$. Yan et al. ${ }^{(35)}$ developed WHtR cut-offs for Asian subjects using BMI as the gold standard (overweight and obesity cut-offs of $24 \mathrm{~kg} / \mathrm{m}^{2}$ 
(a)

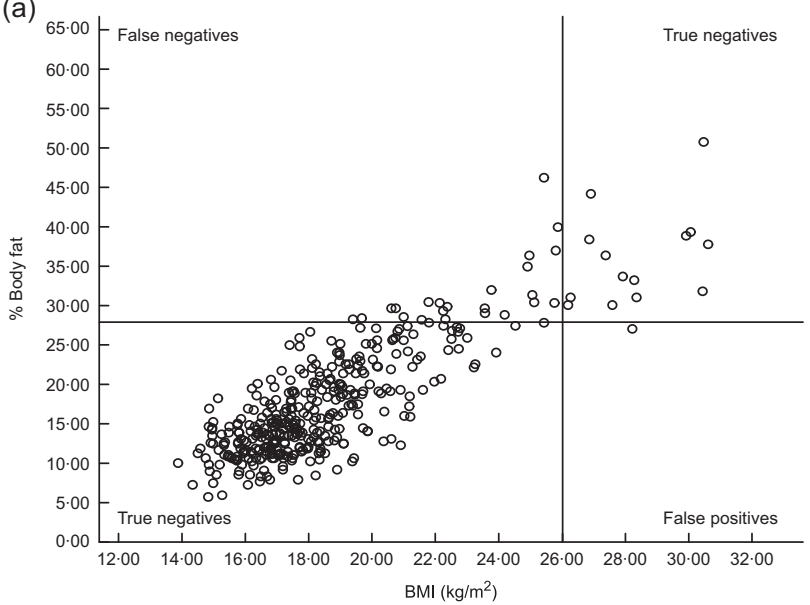

(b)

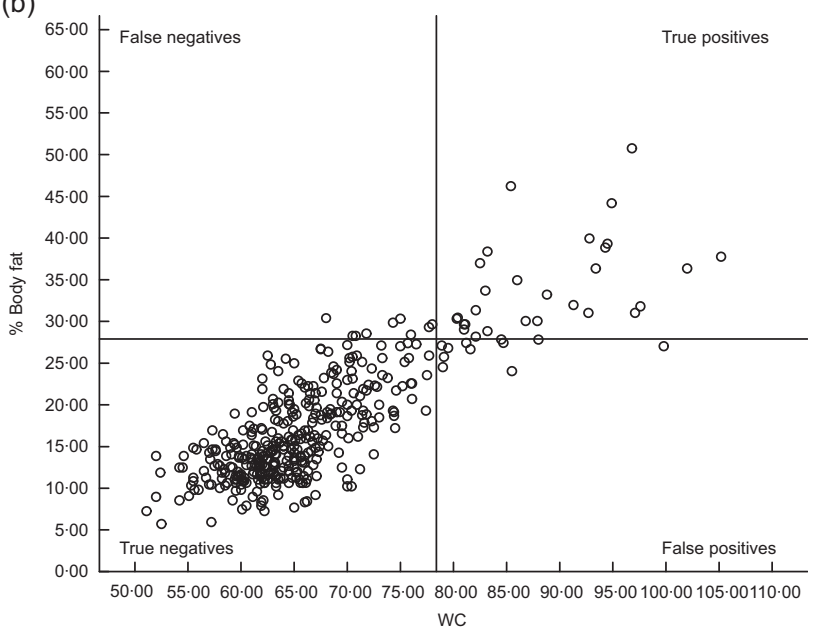

(c)

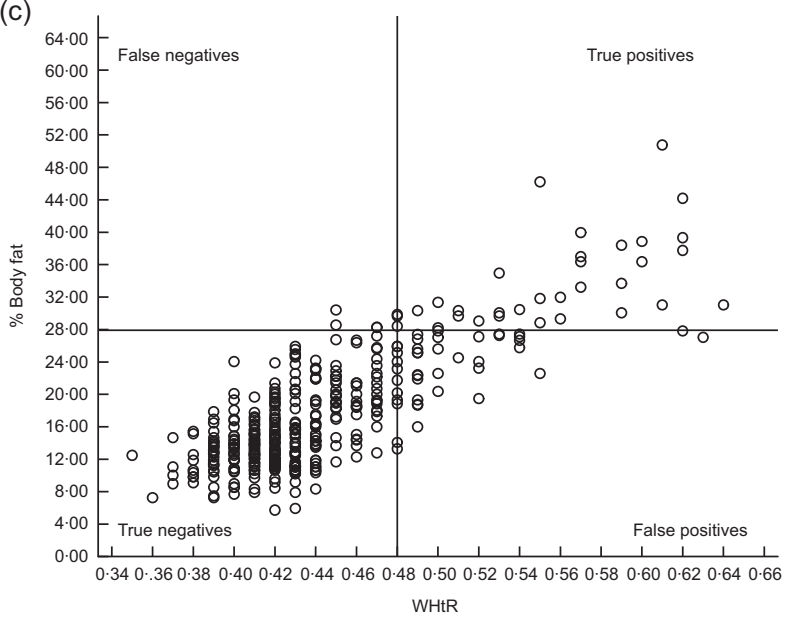

Fig. 1 (a-c) Comparing existing BMl and waist circumference (WC) obesity cut-offs and the newly developed waist-to-height ratio (WHtR) obesity cut-off, in its ability to identify children $\geq 95$ th percentile for percentage body fat (\%BF), in our sample of 12-year-old boys. Horizontal line marks \%BF $\geq 95$ th percentile (27.9\%); vertical lines represent (a) the International Obesity Task Force cut-off for BMI $\left(\geq 26.02 \mathrm{~kg} / \mathrm{m}^{2}\right)$, (b) the $\geq 95$ th percentile for WC using Australian data $(\geq 78.4 \mathrm{~cm})$ and (c) the WHtR cut-off $(\geq 0 \cdot 48)$ and $28 \mathrm{~kg} / \mathrm{m}^{2}$, respectively, at the age of 18 years). Their study found that the WHtR to identify overweight was the same for male and female subjects aged 8-18 years, at $0 \cdot 445$, whereas for obesity, it was $0 \cdot 485$ for male subjects and 0.475 for female subjects at 8-18 years of age.

Selected anthropometric variables, blood lipids and BP were compared between WHtR groups 1, 2 and 3 for male and female subjects (Tables $5 \mathrm{a}$ and $\mathrm{b}$ ). For each variable, for both sexes, it was found that mean values were higher in WHtR group 3 (except for HDL-C, where it was lowest in group 3). For the anthropometric variables, all differences were statistically significant. This was also the case for blood lipid variables TAG and HDL-C and SBP. Despite these differences in means, no significant correlations were found between anthropometric variables and blood lipids or BP. This supports the argument that while weight may have an influence, the cause of high lipid profiles may also be attributable to genetics and be independent of weight or excess $\mathrm{BF}^{(9)}$. These children may also not present with high blood lipids and BP until later in life, which increases the need to conduct longitudinal studies involving children screened as overweight or obese based on \%BF.

There are a number of limitations to the present study. First, in the present analysis, \%BF was calculated using skinfolds, but the subjects were then classified as overweight or obese using British \%BF percentiles that were calculated using bioelectrical impedance analysis (BIA) ${ }^{(22)}$. This may have resulted in some inaccuracy or bias that could not be measured as the data set analysed in the present study could not be cross-referenced with BIA-derived \%BF estimates. There are a limited number of articles that compare $\% \mathrm{BF}$ estimates using BIA and skinfolds in children. However, in an investigation conducted by Goss et al. ${ }^{(43)}$, it was found that $\% \mathrm{BF}$ did not differ significantly between \%BF determined by skinfolds (using child-specific equations) or BIA.

The second limitation of the present study is that an indirect estimate of $\% \mathrm{BF}$ is being compared with WHtR, which is again an indirect measure of abdominal adiposity. Although this may be the case, WC and skinfold measures have been validated against direct measures of $\% \mathrm{BF}$ and visceral fat mass using dual-energy X-ray absorptiometry (DEXA) and magnetic resonance imaging (MRI) ${ }^{(39,44,45)}$. The use of skinfold measures to calculate \%BF can also be associated with high inter- and intra-observer variability. However, in large population health studies involving children (which are limited in Australia), skinfold measures prove to be a relatively simple, cost-effective and feasible option to obtain \%BF. A study conducted by Steinberger et al. (2005) has shown that \%BF calculated from triceps and subscapular skinfolds, using the equations of Slaughter et al. (1988), to be strongly correlated with \%BF was determined by DEXA $(r=0.93$ for male subjects and 0.92 for female subjects, $P<0 \cdot 0001$ ), thus increasing the validity of using skinfold measures at the population level ${ }^{(24,45)}$. Nevertheless, the standard deviation of the difference between $\% \mathrm{BF}$ from DEXA and \%BF from skinfolds in this study was 
Table 4 ROC analyses comparing the sensitivity and specificity of new WHtR cut-offs against existing BMI (IOTF) and WC (Australian percentile) cut-offs for obesity by sex and selected age groups

\begin{tabular}{|c|c|c|c|c|c|c|}
\hline \multirow[b]{2}{*}{$\begin{array}{l}\text { Age group } \\
\text { (years) }\end{array}$} & \multicolumn{3}{|c|}{ Males } & \multicolumn{3}{|c|}{ Females } \\
\hline & $\begin{array}{c}\text { Measure } \\
\text { (cut-off to define obesity) }\end{array}$ & $\begin{array}{l}\text { Sensitivity } \\
(\%)\end{array}$ & $\begin{array}{l}\text { Specificity } \\
(\%)\end{array}$ & $\begin{array}{c}\text { Measure } \\
\text { (cut-off to define obesity) }\end{array}$ & $\begin{array}{l}\text { Sensitivity } \\
(\%)\end{array}$ & $\begin{array}{l}\text { Specificity } \\
(\%)\end{array}$ \\
\hline \multirow[t]{3}{*}{9} & BMI $\left(22 \cdot 77 \mathrm{~kg} / \mathrm{m}^{2}\right)$ & 45 & 99 & BMI $\left(22 \cdot 8 \mathrm{~kg} / \mathrm{m}^{2}\right)$ & 36 & 99 \\
\hline & WC $(69.7 \mathrm{~cm})$ & 60 & 97 & $W C(69.9 \mathrm{~cm})$ & 55 & 93 \\
\hline & $\mathrm{WHtR}(\geq 0.48)$ & 95 & 90 & $\mathrm{WHtR}(\geq 0.47)$ & 91 & 82 \\
\hline \multirow[t]{3}{*}{12} & BMI $\left(26.02 \mathrm{~kg} / \mathrm{m}^{2}\right)$ & 38 & 97 & BMI $\left(26.67 \mathrm{~kg} / \mathrm{m}^{2}\right)$ & 40 & 99 \\
\hline & WC $(78.4 \mathrm{~cm})$ & 76 & 97 & WC $(76.6 \mathrm{~cm})$ & 67 & 96 \\
\hline & WHtR ( $\geq 0.48)$ & 89 & 89 & WHtR ( $\geq 0.47)$ & 73 & 89 \\
\hline \multirow[t]{3}{*}{15} & BMI $\left(28 \cdot 3 \mathrm{~kg} / \mathrm{m}^{2}\right)$ & 33 & 99 & BMI $\left(29 \cdot 1 \mathrm{~kg} / \mathrm{m}^{2}\right)$ & 10 & 97 \\
\hline & WC $(85.6 \mathrm{~cm})$ & 67 & 97 & WC $(82.2 \mathrm{~cm})$ & 29 & 96 \\
\hline & WHtR $(\geq 0.48)$ & 87 & 93 & WHtR $(\geq 0.47)$ & 62 & 83 \\
\hline
\end{tabular}

ROC, receiver-operating characteristic; WHtR, waist-to-height ratio; IOTF, International Obesity Task Force; WC, waist circumference.

Table 5a Summary statistics for blood lipids and blood pressure, male subjects by WHtR groups

\begin{tabular}{|c|c|c|c|c|c|}
\hline Sex & Variables & WHtR groups & $n$ & Mean & SD \\
\hline \multirow[t]{4}{*}{ Male } & \multirow[t]{3}{*}{ Age (years) } & 1 & 1001 & $12 \cdot 56^{\star}$ & $2 \cdot 46$ \\
\hline & & 2 & 211 & $11 \cdot 85^{\star}$ & $2 \cdot 45$ \\
\hline & & 3 & 183 & $12 \cdot 16$ & $2 \cdot 11$ \\
\hline & \multirow[t]{3}{*}{ Weight (kg) } & 1 & 1001 & $42 \cdot 60^{*}$ & $13 \cdot 00$ \\
\hline & & 2 & 211 & $44 \cdot 40^{*}$ & $14 \cdot 60$ \\
\hline & & 3 & 183 & $53 \cdot 30^{*}$ & $16 \cdot 70$ \\
\hline & \multirow[t]{3}{*}{ Height (cm) } & 1 & 1001 & $152 \cdot 80^{*}$ & $15 \cdot 70$ \\
\hline & & 2 & 211 & $148 \cdot 50^{*}$ & $15 \cdot 60$ \\
\hline & & 3 & 183 & $151 \cdot 10$ & $14 \cdot 40$ \\
\hline & \multirow[t]{3}{*}{ WC (cm) } & 1 & 1001 & $63 \cdot 90^{*}$ & $6 \cdot 90$ \\
\hline & & 2 & 211 & $68 \cdot 70^{\star}$ & $7 \cdot 40$ \\
\hline & & 3 & 183 & $78 \cdot 90^{\star}$ & $10 \cdot 10$ \\
\hline & \multirow[t]{3}{*}{ Body fat (\%) } & 1 & 1001 & $13 \cdot 30^{*}$ & $3 \cdot 80$ \\
\hline & & 2 & 211 & $17 \cdot 50^{*}$ & $4 \cdot 63$ \\
\hline & & 3 & 183 & $25 \cdot 50^{\star}$ & $7 \cdot 50$ \\
\hline & \multirow[t]{3}{*}{ T-Chol (mmol/l) } & 1 & 356 & $4 \cdot 43$ & $0 \cdot 78$ \\
\hline & & 2 & 90 & $4 \cdot 44$ & $0 \cdot 75$ \\
\hline & & 3 & 73 & $4 \cdot 45$ & $0 \cdot 74$ \\
\hline & \multirow[t]{3}{*}{ TAG $(\mathrm{mmol} / \mathrm{l})$} & 1 & 338 & $0 \cdot 65^{\star}$ & 0.27 \\
\hline & & 2 & 78 & 0.69 & $0 \cdot 36$ \\
\hline & & 3 & 70 & $0 \cdot 78^{*}$ & 0.38 \\
\hline & \multirow[t]{3}{*}{ LDL-C (mmol/l) } & 1 & 335 & $2 \cdot 66$ & $0 \cdot 70$ \\
\hline & & 2 & 78 & $2 \cdot 71$ & 0.68 \\
\hline & & 3 & 67 & $2 \cdot 77$ & 0.65 \\
\hline & \multirow[t]{3}{*}{$\mathrm{HDL}-\mathrm{C}(\mathrm{mmol} / \mathrm{l})$} & 1 & 334 & $1 \cdot 48^{*} t$ & $0 \cdot 10$ \\
\hline & & 2 & 78 & $1 \cdot 38 t$ & 0.27 \\
\hline & & 3 & 67 & $1 \cdot 30^{*}$ & 0.26 \\
\hline & \multirow{3}{*}{$\mathrm{SBP}(\mathrm{mmHg})$} & 1 & 976 & 109 & 14 \\
\hline & & 2 & 203 & 111 & 15 \\
\hline & & 3 & 175 & 112 & 14 \\
\hline & \multirow[t]{3}{*}{$\mathrm{DBP}(\mathrm{mmHg})$} & 1 & 975 & 77 & 13 \\
\hline & & 2 & 202 & 77 & 13 \\
\hline & & 3 & 176 & 79 & 12 \\
\hline
\end{tabular}

WHtR, waist-to-height ratio; WC, waist circumference; T-Chol, total cholesterol; LDL-C, LDL cholesterol; HDL-C, HDL cholesterol; SBP, systolic blood pressure; DBP, diastolic blood pressure.

WHtR group cut-offs: male subjects $1(<0 \cdot 46), 2(0 \cdot 46-0 \cdot 47), 3(\geq 0 \cdot 48)$

${ }^{*}$ and + denote statistically significant differences between WHtR cut-offs for a particular variable $(P<0.05)$.

approximately $5 \%$ in both sexes, indicating that caution should be applied at the individual level.

Tanner staging was not collected from this sample of children. It is possible that a proportion of girls in the youngest age group (particularly those who are obese) may have already reached puberty ${ }^{(46)}$.
Table 5b Summary statistics for blood lipids and blood pressure, female subjects by WHtR groups

\begin{tabular}{|c|c|c|c|c|c|}
\hline Sex & Variables & $\mathrm{WH}$ tR group & $n$ & Mean & SD \\
\hline \multirow[t]{33}{*}{ Female } & \multirow[t]{3}{*}{ Ages (years) } & 1 & 995 & $12 \cdot 39$ & $2 \cdot 36$ \\
\hline & & 2 & 223 & $12 \cdot 24$ & $2 \cdot 62$ \\
\hline & & 3 & 160 & 12.06 & 2.53 \\
\hline & \multirow[t]{3}{*}{ Weight $(\mathrm{kg})$} & 1 & 995 & $41 \cdot 20^{*}$ & $10 \cdot 70$ \\
\hline & & 2 & 223 & $68 \cdot 50^{*}$ & $6 \cdot 40$ \\
\hline & & 3 & 160 & $50 \cdot 80^{*}$ & 14.50 \\
\hline & \multirow[t]{3}{*}{ Height (cm) } & 1 & 995 & $149 \cdot 90$ & $12 \cdot 40$ \\
\hline & & 2 & 223 & $147 \cdot 80$ & 13.60 \\
\hline & & 3 & 160 & $148 \cdot 40$ & $12 \cdot 70$ \\
\hline & \multirow[t]{3}{*}{ WC (cm) } & 1 & 995 & $61 \cdot 40^{*}$ & 5.90 \\
\hline & & 2 & 223 & $68 \cdot 50^{*}$ & $6 \cdot 40$ \\
\hline & & 3 & 160 & $76 \cdot 30^{*}$ & $8 \cdot 30$ \\
\hline & \multirow[t]{3}{*}{ Body fat (\%) } & 1 & 995 & $18 \cdot 70^{*}$ & $4 \cdot 70$ \\
\hline & & 2 & 223 & $23 \cdot 80^{*}$ & $5 \cdot 60$ \\
\hline & & 3 & 160 & $27 \cdot 70^{*}$ & 5.90 \\
\hline & \multirow[t]{3}{*}{ T-Chol (mmol/l) } & 1 & 324 & $4 \cdot 67$ & 0.69 \\
\hline & & 2 & 77 & $4 \cdot 65$ & 0.85 \\
\hline & & 3 & 59 & $4 \cdot 60$ & 0.68 \\
\hline & \multirow[t]{3}{*}{$\mathrm{TG}(\mathrm{mmol} / \mathrm{l})$} & 1 & 306 & 0.73 & 0.32 \\
\hline & & 2 & 72 & 0.74 & 0.32 \\
\hline & & 3 & 52 & 0.96 & 0.76 \\
\hline & \multirow[t]{3}{*}{ LDL-C (mmol/l) } & 1 & 300 & $2 \cdot 85$ & 0.68 \\
\hline & & 2 & 71 & $2 \cdot 84$ & 0.63 \\
\hline & & 3 & 52 & $2 \cdot 82$ & 0.61 \\
\hline & \multirow{3}{*}{$\mathrm{HDL}-\mathrm{C}(\mathrm{mmol} / \mathrm{l})$} & 1 & 300 & $1 \cdot 49^{*}$ & 0.31 \\
\hline & & 2 & 70 & $1 \cdot 43$ & 0.27 \\
\hline & & 3 & 51 & $1 \cdot 32^{*}$ & 0.28 \\
\hline & \multirow[t]{3}{*}{$\mathrm{SBP}(\mathrm{mmHg})$} & 1 & 974 & $108^{*}$ & 12 \\
\hline & & 2 & 217 & $108 t$ & 13 \\
\hline & & 3 & 156 & $112^{*}+$ & 14 \\
\hline & \multirow[t]{3}{*}{$\mathrm{DBP}(\mathrm{mmHg})$} & 1 & 974 & 76 & 12 \\
\hline & & 2 & 216 & 78 & 12 \\
\hline & & 3 & 156 & 80 & 14 \\
\hline
\end{tabular}

WHtR, waist-to-height ratio; WC, waist circumference; T-Chol, total cholesterol; LDL-C, LDL cholesterol; HDL-C, HDL cholesterol; SBP, systolic blood pressure; DBP, diastolic blood pressure.

WHtR group cut-offs: female subjects $1(<0 \cdot 45), 2(0 \cdot 45-0 \cdot 46), 3(\geq 0 \cdot 47)$.

* and + denote statistically significant differences between WHtR cut-offs for a particular variable $(P<0.05)$.

\section{Conclusion}

The present study has shown that the WHtR is strongly related to $\% \mathrm{BF}$ and distribution of $\mathrm{BF}$, which are associated with increased cardiovascular health risks. Cut-offs of 0.46 and 0.48 to mark overweight and obesity, 
respectively, in boys and 0.45 and 0.47 in girls have been shown to be superior to the widely used BMI for several reasons. WHtR is independent of age and eliminates the need for percentile charts; WHtR is far more sensitive than $\mathrm{BMI}$ in identifying children with $\geq 95$ th percentile for $\% \mathrm{BF}$; WHtR is highly sensitive and specific in identifying children classified as overweight or obese by BMI. Our results also show that children in the most at risk WHtR group consistently had higher mean values for anthropometry, blood lipids and BP than the least at risk WHtR group.

The WHtR and the newly developed overweight and obesity cut-offs would be especially useful in communitybased studies involving large cohorts of children. Proxy measures of subcutaneous and intra-abdominal adipose tissue such as mid-abdominal skinfolds are more difficult to measure because they require trained technicians and repeated measures to avoid technical errors. Height and WC, on the other hand, are much simpler to collect; WHtR is straightforward to calculate; WHtR is strongly correlated with anthropometric measures of abdominal fat and it is highly sensitive in identifying children at a population level, regardless of age, with higher $\% \mathrm{BF}$ and at greater risk of developing weight-related CVD at an earlier age. Although we believe that using WHtR has significant advantages, the cut-offs developed here need validation in more recent cohorts.

\section{Acknowledgements}

Sources of funding: S.N. was supported by a joint research scholarship from the University of Queensland. Conflict of interest: The authors declare that they have no conflict of interest. Authors' contributions: All authors were involved in study design, data analysis and preparation of the manuscript.

\section{References}

1. Margery A, Daniels L \& Boulton T (2001) Prevalence of overweight and obesity in Australian children and adolescents: reassessment of the 1985 and 1995 data against standard definitions. Med J Aust 174, 561-564.

2. Must A, Spadana J, Coakley E et al. (1999) The disease burden associated with overweight and obesity. JAMA 282, 1523-1529.

3. Dietz WH (1998) Health consequences in youth: childhood predictors of adult disease. Pediatrics 101, Suppl., 518-525.

4. Katzmarzyk PT, Srinivasan SR, Chen W et al. (2004) Body mass index, waist circumference and clustering of cardiovascular risk factors in bi-racial sample of children and adolescents. Pediatrics 114, 198-205.

5. Williams DP, Going SB, Lohman TG et al. (1992) Body fatness and risk for elevated blood pressure, total cholesterol and serum lipoprotein ratios in children and adolescents. Am J Public Health 82, 358-563.

6. Bacha F, Saad R, Gungor N et al. (2003) Obesity, regional fat distribution and Syndrome $\mathrm{X}$ in obese black versus white adolescents: race differential in diabetogenic and atherogenic risk factors. J Clin Endocrinol Metab 88, 2534-2540.
7. Despres J, Morrjani S, Lupien P et al. (1990) Regional distribution of body fat, plasma lipoproteins and cardiovascular disease. Arterioscler Thromb Vasc Biol 10, 497-511.

8. Saelens BE, Seeley RJ, Schaick KV et al. (2007) Visceral abdominal fat is correlated with whole body fat and physical activity among 8 -y-old children at risk of obesity. Am J Clin Nutr 85, 46-53.

9. Freedman DS, Khan LK, Dietz WH et al. (2001) Relationship of childhood obesity to coronary heart disease risk factors in adulthood: the Bogalusa Heart Study. Pediatrics 108, 712-718.

10. Gibson RS (2005) Principles of Nutritional Assessment, 2nd ed. New York: Oxford University Press.

11. World Health Organization Expert Committee (1995) Physical Status: The Use and Interpretation of Anthropometry. Geneva: WHO.

12. Neovius M, Linne $Y$ \& Rossner S (2005) BMI, waist circumference and waist-hip-ratio as diagnostic tests for fatness in adolescents. Int J Obes 29, 161-169.

13. Goh VHH, Tain CF, Ton TYY et al. (2004) Are BMI and other anthropometric measures appropriate as indices for obesity? A study in an Asian population. J Lipid Res $\mathbf{4 5}$, 1892-1898.

14. Hall DMB \& Cole TJ (2006) What use is the BMI. Arch Dis Child 91, 283-286.

15. Janssen I \& Katzmarzyk PT (2004) Waist circumference and not body mass index explains obesity-related health risk. Am J Clin Nutr 79, 379-384.

16. Centers for Disease Control and Prevention (2000) Overview of the CDC Growth Charts. http://www.cdc.gov (accessed December 2007).

17. Cole TJ, Bellizzi MC, Flegal KM et al. (2000) Establishing a standard definition for child overweight and obesity worldwide: international survey. BMJ 320, 1240-1243.

18. Hsieh S, Yoshinaga H \& Muto T (2003) Waist to height ratio, a simple and practical index for assessing central fat distribution and metabolic risk in Japanese men and women. Int J Obes 27, 610-616.

19. Nambiar S, Truby H, Abbott R et al. (2009) Validating the waist-height ratio and developing centiles for use amongst children and adolescents. Acta Paed 98, 148-152.

20. Pyke JE (1985) Australian Health and Fitness Survey 1985. Parkside, SA: The Australian Council for Health, Physical Education and Recreation Inc.

21. Slaughter M, Lohman T, Boileau R et al. (1988) Skinfold equations for estimation of body fatness in children and youth. Hum Biol 60, 709-723.

22. McCarthy H, Cole T, Fry T et al. (2006) Body fat reference curves for children. Int J Obes 30, 598-602.

23. Mueller WH, Harrist RB, Doyle SR et al. (2004) Percentiles of body composition from bioelectrical impedance and body measurements in US adolescents 8-17 years old: Project HeartBeat! Am J Hum Biol 16, 135-150.

24. Reilly JJ, Wilson J \& Durmin JVGA (1995) Determination of body composition from skinfold thickness: a validation study. Arch Dis Child 73, 305-310.

25. Lindsey CC, Graham MR, Johnson TP et al. (2004) A clinical comparison of calculated versus direct measurement of low-density lipoprotein cholesterol level. Pharmacotherapy 24, 167-172.

26. Garbin CP (not dated) Bivariate Correlation Analyses and Comparisons; Cal's Computator Program. http://wwwclass.unl.edu/psycrs/statpage/comp.html (accessed February 2009).

27. Ashwell M (2005) Waist to height ratio and the Ashwell shape chart could predict risks of obesity in adults and children in all ethnic groups. Nutr Food Sci 36, 359-364.

28. Ashwell M \& Hsieh SD (2005) Six reasons why the waist-toheight ratio is a rapid and effective global indicator for the 
health risks of obesity and how its use could simplify the international public health message on obesity. Int J Food Sci Nutr 56, 303-307.

29. Freedman DS, Kahn HS, Mei Z et al. (2007) Relation of body mass index and waist-to-height ratio to cardiovascular disease risk factors in children and adolescents: the Bogalusa Heart Study. Am J Clin Nutr 86, 33-40.

30. Hsieh S \& Yoshinaga H (1995) Abdominal fat distribution and coronary heart disease risk factors in men - waist/ height ratio as a simple and useful predictor. Int $J$ Obes Relat Metab Disord 19, 585-589.

31. Hsieh SD \& Moto T (2006) Metabolic syndrome in Japanese men and women with special reference to the anthropometric criteria for the assessment of obesity: proposal to use the waist to height ratio. Prev Med 42, 135-139.

32. Hsieh SD \& Muto T (2005) The superiority of waistto-height ratio as an anthropometric index to evaluate clustering of coronary risk factors among non-obese men and women. Prev Med 40, 216-220.

33. Hsieh SD \& Yoshinaga H (1995) Waist/height ratio as a simple and useful predictor of coronary heart disease risk factors in women. Int Med 34, 1147-1152.

34. McCarthy H \& Ashwell M (2006) A study of central fatness using waist-to-height ratios in UK children and adolescents over two decades supports the sample message - 'keep your waist circumference to less than half your height. Int J Obes 30, 988-992.

35. Yan W, Bingxian H, Hua Y et al. (2007) Waist-to-height ratio is an accurate and easier index for evaluating obesity in children and adolescents. Obesity 15, 748-752.

36. Hara M, Saitou E, Iwata F et al. (2002) Waist-to-height ratio is the best predictor of cardiovascular disease risk factors in Japanese schoolchildren. J Arthroscl and Thromb 9, 127-132.
37. Ho SY, Lam TH \& Janus ED (2003) Waist to stature ratio is more strongly associated with cardiovascular risk factors than other simple anthropometric indices. Ann Epidemiol 13, 683-691.

38. Daniels SR, Morrison JA, Sprecher DL et al. (1999) Association of body fat distribution and cardiovascular risk factors in children and adolescents. Circulation 99, 541-545.

39. Goran M, Gower B, Treuth M et al. (1998) Prediction of intra-abdominal and subcutaneous abdominal adipose tissue in healthy pre-pubertal children. Int J Obes 22, 549-558.

40. Goran M \& Gower BA (1999) Relation between visceral fat and disease risk in children and adolescents. Am J Clin Nutr 70, Suppl., 149S-156S.

41. Neovius M \& Rasmussen F (2008) Evaluation of BMI-based classification of adolescent overweight and obesity: choice of percentage body fat cut-offs exerts a large influence. The COMPASS study. Eur J Clin Nutr 62, 1201-1207.

42. Eissenmann JC (2005) Waist circumference percentiles for 7-to-15-year-old Australian children. Acta Pediatrica 94, $1182-1185$.

43. Goss F, Robertson R, Williams A et al. (2003) A comparison of skinfolds and leg-to-leg bioelectrical impedance for the assessment of body composition in children. Dyn Med $\mathbf{2}, 5$.

44. Brambilla P, Bedogni G, Moreno LA et al. (2006) Cross validation of anthropometry against magnetic resonance imaging for the assessment of visceral and subcutaneous adipose tissue in children. Int J Obes 30, 23-30.

45. Steinberger J, Jocobs DR Jr, Raatz S et al. (2005) Comparison of body fatness measurements by BMI and skinfolds vs dual $\mathrm{X}$-ray absorptiometry and their relation to cardiovascular risk factors in adolescents. Int J Obes 29, 1346-1352.

46. Kaplowitz PB, Slora EJ, Wasserman RC et al. (2001) Earlier onset of puberty in girls: relation to increased body mass index and race. Pediatrics 108, 347-353. 